\title{
El derecho al trabajo en la jurisprudencia reciente interamericana
}

\section{POR VICTORIA FLORES BELTRÁN(*)}

\begin{abstract}
Sumario: I. Introducción.- II. Los casos.- III. Estándares sobre el derecho al trabajo.- IV. Medidas de reparación.- V. Conclusiones.- VI. Bibliografía.
\end{abstract}

Resumen: la segmentación de los derechos humanos en civiles y políticos, por un lado, y económicos, sociales y culturales, por el otro, tuvo un impacto concreto en la forma en la que se jerarquizaron unos por sobre otros, algo que se evidenció en los distintos grados de exigibilidad y justicibialidad. La jurisprudencia reciente de la Corte Interamericana de Derechos Humanos generó una ruptura de este paradigma en materia de derecho al trabajo, al dotarlo de contenido y considerarlo un derecho autónomo, exigible de forma directa ante el Sistema Interamericano de protección. El objetivo de este artículo es dar cuenta de la evolución jurisprudencial del máximo tribunal regional sobre derecho al trabajo, sistematizando los estándares que surgen de las sentencias. Al mismo tiempo, se intentará esbozar algunas conclusiones en materia de reparaciones y de los desafíos que se vislumbran.

Palabras claves: derecho al trabajo - derechos económicos, sociales, culturales y ambientales - exigibilidad - justicibialidad

\section{The right to work in the recent inter-american jurisprudence}

Abstract: the segmentation of human rights into civil and political rights on the one hand and economic, social and cultural rights on the other, has had a concrete impact on the way they were ranked placing some above others, something that was evident in the degrees of enforceability and justiciability. The recent jurisprudence of the Inter-American Court of Human Rights (Inter-American Court) caused a rupture in this paradigm regarding the right to work, by providing it with content and considering it an autonomous right, directly enforceable before the InterAmerican system of protection. The aim of this paper is to account for the evolution of the jurisprudence of the highest regional court with regards to the right to work,

$\left({ }^{*}\right)$ Abogada, Universidad de Buenos Aires (UBA). Prof. del Departamento de Derecho del Trabajo y de la Seguridad Social, Facultad de Derecho, Universidad de Buenos Aires (UBA). 
systematizing the standards that emerge from the sentences. At the same time, it will seek to draw some conclusions on the reparations and challenges that are looming.

Keywords: right to work - economic, social, cultural and environmental rightsenforceability - justiciability

\section{Introducción}

El artículo 26 de la Convención Americana sobre Derechos Humanos (en adelante, $\mathrm{CADH}$ ) establece:

Los Estados Partes se comprometen a adoptar providencias, tanto a nivel interno como mediante la cooperación internacional, especialmente económica y técnica, para lograr progresivamente la plena efectividad de los derechos que se derivan de las normas económicas, sociales y sobre educación, ciencia y cultura, contenidas en la Carta de la Organización de los Estados Americanos, reformada por el Protocolo de Buenos Aires, en la medida de los recursos disponibles, por vía legislativa u otros medios apropiados.

Esta redacción y la propia organización de la Convención Americana sobre Derechos Humanos (en adelante, $\mathrm{CADH}$ ) se inscribe en la tradición de la segmentación de los derechos humanos y su caracterización alrededor de las llamadas generaciones de derechos, categorización superada en la propia jurisprudencia de la Corte Interamericana de Derechos Humanos (Corte IDH).

Por un lado, se ubicaban los derechos civiles y políticos, entendidos como de carácter operativo y que generarían en los Estados obligaciones negativas de abstención y, por el otro, los derechos económicos, sociales, culturales y ambientales (DESCA), inscriptos en una lógica programática, que requerirían de los Estados medidas positivas para su consecución (Cançado Trindade, 1997, p. 54). Esto, nuevamente, se evidencia en el modo en el que la CADH prioriza los derechos civiles y políticos (Pinto, 2014, p. 35). Además de superada, esta clasificación y caracterización es desacertada, puesto que los derechos civiles y políticos requieren de acciones positivas por parte de los Estados, así como los DESCA — una vez alcanzado el bien que constituye el objeto del derecho- demandan que el Estado se abstenga de realizar cualquier acto que los pudiese afectar (Abramovich y Courtis, 2009).

De esta manera, las posibilidades de justiciabilidad de los DESCA en el sistema interamericano estuvo ligada, esencialmente, a los derechos civiles y políticos, o sea, a una justicibialidad indirecta. Sin embargo, tanto la Comisión Interamericana de Derechos Humanos (CIDH) como la propia Corte Interamericana de Derechos Humanos dieron señales de avances hacia el fortalecimiento y autonomía de 
los DESCA. La creación en el ámbito de la CIDH de la Relatoría Especial sobre los Derechos Económicos, Sociales, Culturales y Ambientales (REDESCA); la Opinión Consultiva No 23 sobre Medio Ambiente y Derechos Humanos; el Informe Empresas y Derechos Humanos: estándares interamericanos y la solicitud de una Opinión Consultiva sobre "Alcance de las obligaciones de los estados, bajo el sistema interamericano, sobre las garantías a la libertad sindical, su relación con otros derechos y aplicación desde una perspectiva de género", constituyen algunos de los hitos del camino de consolidación de los DESCA. Ya en el caso "Acevedo Buendía", la Corte había afirmado su competencia para entender respecto de las violaciones al artículo 26 de la $\mathrm{CADH}$, a pesar de que finalmente resolvió en función de la violación de derechos civiles y políticos (Calderón Gamboa, 2018, p. 339).

En el año 2017 y en línea con la doctrina que se cimenta en la universalidad, integralidad e interdependencia de los Derechos Humanos (Pinto, 2004, p. 31), la Corte IDH invocó el principio iuria novit curia en el caso "Lagos del Campo vs. Perú" (1), y se adentró a analizar la violación del artículo 26, en la que es la primera sentencia que aborda el derecho al trabajo como un derecho autónomo, plenamente exigible en el ámbito del Sistema Interamericano. A esta sentencia le siguieron, muy cerca en el tiempo, los casos "Trabajadores cesados de Petroperú y otros vs. Perú" (2) y "San Miguel Sosa y otras vs. Venezuela" (3), en tanto, en el año 2020, la Corte se pronunció en los casos "Spoltore vs. Argentina" (4) y "Empleados de la fábrica de fuegos en Santo Antonio de Jesús vs. Brasil" (5). Esto constituyó no solo la puerta de ingreso para la plena exigibilidad de los DESCA, sino un diálogo con el contexto y la realidad de la región. Es que, tal y como lo señaló la propia Corte IDH, los tratados de derechos humanos son instrumentos vivos,

(1) Corte IDH, “Caso Lagos del Campo vs. Perú", Sentencia de 31 de agosto de 2017, Serie C No 340. Recuperado de http://www.corteidh.or.cr/docs/casos/articulos/seriec_340_esp.pdf [Fecha de consulta: abril de 2021].

(2) Corte IDH, "Caso Trabajadores Cesados de Petroperú y otros vs. Perú", Sentencia de 23 de noviembre de 2017, Serie C No 344. Recuperado de http://www.corteidh.or.cr/docs/casos/articulos/ seriec_344_esp.pdf

(3) Corte IDH, "Caso San Miguel Sosa y otras vs. Venezuela", Sentencia de 8 de febrero de 2018, Serie C No 348. Recuperado de http://www.corteidh.or.cr/docs/casos/articulos/seriec_344_esp.pdf [Fecha de consulta: abril de 2021].

(4) Corte IDH, “Caso Spoltore vs. Argentina”, Sentencia de 9 de junio de 2020, Serie C No 404. Recuperado de https://www.corteidh.or.cr/docs/casos/articulos/seriec_404_esp.pdf [Fecha de consulta: abril de 2021].

(5) Corte IDH, "Caso de los Empleados de la Fábrica de Fuegos de Santo Antônio de Jesus vs. Brasil". Sentencia de 15 de julio de 2020. Serie C No. 407. Recuperado de https://www.corteidh.or.cr/ docs/casos/articulos/seriec_407_esp.pdf [Fecha de consulta: abril de 2021]. 
cuya interpretación tiene que acompañar la evolución de los tiempos y las condiciones de vida actuales (6), en línea con las pautas que emanan del artículo 29 de la CADH.

En este sentido, si algo evidenció la pandemia por la enfermedad COVID-19 fue la desprotección en materia de DESCA en la población. Los mecanismos de protección social que debieron poner en marcha numerosos países a partir de la crisis social, económica y las medidas de restricción impuestas para contener la circulación del virus, dan cuenta de la centralidad del trabajo para la garantía de otros derechos y para la dignidad de las personas.

En lo que hace al objeto de este trabajo, los casos involucran diversas violaciones de derechos humanos, además del derecho al trabajo. En el primero, se cuestiona la responsabilidad internacional de Perú por la violación a los derechos de libertad de expresión, libertad de asociación y el derecho a las garantías judiciales. En el segundo, se analiza también la violación a los derechos de debido proceso y de tutela judicial efectiva. En el tercero, se demanda a Venezuela por la violación de la libertad de expresión y los derechos políticos. "Spoltore", en cambio, versa, además, sobre el derecho a las garantías judiciales y a la protección judicial y "Empleados de la fábrica de fuegos", sobre el derecho a la integridad personal, derechos de la niña y del niño, igualdad y no discriminación, protección judicial y garantías judiciales.

Las sentencias de la Corte IDH bajo análisis refuerzan la protección del derecho al trabajo a nivel regional, en línea con el desarrollo que tiene lugar en el marco del sistema universal de protección de derechos humanos. Así, el Comité de Derechos Económicos, Sociales y Culturales (Comité DESC) —en particular a través de la Observación General № 18- definió el contenido y alcance de los artículos $6^{\circ}$ y $7^{\circ}$ del Pacto de Derechos Económicos, Sociales y Culturales (7) (PIDESC), asegurando, entre otras cosas, que "el derecho al trabajo es esencial para la realización de otros derechos humanos y constituye una parte inseparable e inherente de la dignidad humana" (8).

(6) Corte IDH, caso "Lagos del Campo", párr. 41.

(7) PIDESC, artículo 6: "1. Los Estados Partes en el presente Pacto reconocen el derecho a trabajar, que comprende el derecho de toda persona a tener la oportunidad de ganarse la vida mediante un trabajo libremente escogido o aceptado, y tomarán medidas adecuadas para garantizar este derecho. 2. Entre las medidas que habrá de adoptar cada uno de los Estados Partes en el presente Pacto para lograr la plena efectividad de este derecho deberá figurar la orientación y formación técnicoprofesional, la preparación de programas, normas y técnicas encaminadas a conseguir un desarrollo económico, social y cultural constante y la ocupación plena y productiva, en condiciones que garanticen las libertades políticas y económicas fundamentales de la persona humana".

(8) Comité DESC, Observación General No 18 (2005), "El derecho al trabajo" (artículo 6), párr. 1. Recuperado de http://docstore.ohchr.org/SelfServices/FilesHandler.ashx?enc=4slQ6QSmlBEDzF 
Lo reseñado da cuenta de que con estas sentencias la Corte Interamericana de Derechos Humanos se enrola en la tendencia de robustecer el marco protectorio que ampara a trabajadores y trabajadoras, particularmente en materia de estabilidad, condiciones equitativas y satisfactorias de trabajo y no discriminación.

El objetivo de este trabajo es dar cuenta de los avances jurisprudenciales en materia de trabajo por parte de la Corte IDH. A continuación, se presenta un resumen de los casos, a la vez que se destacan los estándares fijados por el Tribunal interamericano y las medidas de reparación.

\section{Los casos}

Los cincos casos bajo análisis ocurrieron en diversos países de la región y por hechos muy diferentes entre sí. También eran distintos los regímenes laborales de los trabajadores y trabajadoras víctimas de las violaciones de sus derechos. En los casos "Lagos del Campo" y "Spoltore" se trataba de una relación laboral entre particulares. En el caso "Trabajadores cesados de Petroperú", eran trabajadores y trabajadoras del sector público, mientras que en "San Miguel Sosa", las trabajadoras tenían un régimen de contratación con el Estado regido por leyes laborales comunes. En "Empleados de la fábrica de fuegos", las y los trabajadores estaban sometidos a un régimen informal de contratación.

A continuación, se desarrollan los hechos y las decisiones de la Corte IDH en cada uno de los casos reseñados.

\section{II.1. Lagos del Campo vs. Perú}

Alfredo Lagos del Campo ocupaba el cargo de presidente del Comité Electoral de una empresa del sector industrial privado de Perú (Ceper-Pirelli)(9). Si bien ese órgano no tenía una naturaleza estrictamente sindical, tenía como objetivo representar los intereses de los trabajadores frente a empleadores.

EovLCuW1a0Szab0oXTdImnsJZZVQfUKxXVisd7Dae\%2fCu\%2b13J25McUdQlf6uyQ1W3AE\%2bzFa wOUH0Ya5xlF\%2fpm4TqHirJhNEIzfEcUOUh\%2bvCuU8AEY7w [Fecha de consulta: abril de 2021].

(9) En las empresas del sector industrial privado de Perú, existía la figura de la Comunidad Industrial —una persona jurídica que nacía como representación del conjunto de los trabajadores-, compuesta por la Asamblea General -integrada por la totalidad de los trabajadores-, el Consejo de la Comunidad —órgano ejecutivo-, el Directorio y el Comité Electoral —encargado de llevar a cabo las elecciones de los miembros del Consejo de la Comunidad y de los representantes ante el Directorio de la empresa-. La Comunidad Industrial tenía por objetivo permitir la participación de los trabajadores en la propiedad, gestión y utilidades de la empresa. 
En junio de 1989, Lagos del Campo fue entrevistado para la revista "La Razón". Allí, se indicó que la víctima había denunciado ante la opinión pública "maniobras liquidadoras de la patronal, quienes utilizando la vacilación de algunos trabajadores llevaron a cabo fraudulentas elecciones al margen del Comité Electoral y sin la participación mayoritaria de los comuneros" (10).

A partir de esas declaraciones, la empresa formuló cargos en su contra por falta laboral grave, lo que habilitaba el despido con causa, y se le impidió participar de una reunión en el Comité, a los fines de analizar la posibilidad de realizar nuevas elecciones. A pesar de que el trabajador tuvo la posibilidad de efectuar un descargo contra las acusaciones de la empresa, su empleador procedió a efectivizar el despido.

El 31 de agosto de 2017, la Corte IDH dictó sentencia mediante la cual declaró que el Estado de Perú violó el derecho a la estabilidad laboral (previsto en el artículo 26 de la $\mathrm{CADH}$ ) en relación con los artículos 1.1, 13 (libertad de expresión), 8 (debido proceso) y 16 (libertad de asociación) de la CADH. Además, se declaró la vulneración de esos otros derechos.

\section{II.2. Trabajadores cesados de Petroperú y otros vs. Perú}

Trabajadores y trabajadoras de las empresas estatales Petróleos del Perú (Petroperú), la Empresa Nacional de Puertos (Enapu), y del Ministerio de Educación y el Ministerio de Economía y Finanzas fueron cesanteados de sus puestos de trabajo. Estos ceses se realizaron a través de programas de racionalización y evaluación de personal, en aplicación de diferentes decretos-leyes aprobados por el Poder Ejecutivo. Los trabajadores promovieron acciones de amparo, que fueron declarados infundados al considerar que los actos impugnados se habrían realizado de acuerdo con la ley vigente. Esa decisión fue luego confirmada por el Tribunal Constitucional de Perú.

El 23 de noviembre de 2017 la Corte IDH dictó sentencia en la que declaró la responsabilidad internacional de Perú por la violación a los derechos a las garantías judiciales y la protección judicial (artículos 8.1 y 25 de la CADH), en relación con el artículo 1.1, así como al derecho al trabajo (artículo 26, CADH) en relación también con el artículo 1.1, con motivo de la falta de respuesta judicial adecuada y efectiva frente a los ceses dispuestos.

(10) Corte IDH, caso “Lagos del Campo", párr. 50. 


\section{II.3. San Miguel Sosa y otras vs. Venezuela}

Rocío San Miguel Sosa, Magally Chang Girón y Thais Coromoto Peña prestaban servicios en el Consejo Nacional de Fronteras (CNF) - dependencia del Ministerio de Relaciones Exteriores de Venezuela-, bajo la figura de un contrato de servicios profesionales por períodos mensuales, semestrales o anuales.

Entre los años 2001 y 2003, distintas organizaciones de la sociedad civil y partidos opositores impulsaron la recolección de firmas para revocar el mandato del entonces presidente de Venezuela, Hugo Chávez. Sosa, Chang Girón y Coromoto Peña firmaron la petición y sus nombres aparecieron luego en una lista, de la que ellas se negaron a retirar sus nombres. A raíz de eso, sus contratos con la CNF fueron rescindidos.

El 8 de febrero de 2018 la Corte IDH declaró la responsabilidad internacional de Venezuela por la violación de los derechos a la participación política (artículo 23.1.b) y c), CADH y libertad de pensamiento y expresión (artículo 13.1, $\mathrm{CADH}$ ), en relación con el principio de no discriminación. Asimismo, consideró vulnerado el derecho al trabajo (artículo 26, CADH) en relación con los derechos a la participación política, a la libertad de expresión y de acceso a la justicia, así como con el principio de no discriminación, reconocidos en los artículos 23.1, 13.1, 8.1, 25.1 y 1.1 de la Convención Americana. Además, concluyó que el Estado es responsable por haber incumplido su obligación de garantizar los derechos de acceso a la justicia y a un recurso efectivo para tutelar los derechos de las víctimas (artículo 25, CADH).

\section{II.4. Spoltore vs. Argentina}

Victorio Spoltore trabajó durante 20 años en una fábrica, hasta que, luego de sufrir un infarto en su lugar de trabajo, tramitó la jubilación anticipada por incapacidad. Un año después y tras un nuevo episodio cardíaco, la autoridad responsable decretó que tenía una incapacidad del $70 \%$ por cardiopatía coronaria severa y depresión neurótica. Con fundamento en esto, procedió a su jubilación.

En el año 1988, Spoltore inició una demanda laboral a los fines de reclamar una indemnización por enfermedad laboral. Por ello, solicitó una reparación del daño moral y una indemnización por la incapacidad. El Tribunal del Trabajo rechazó su pretensión nueve años después de iniciado el proceso. Tres años después, la Suprema Corte de Justicia de la Provincia de Buenos Aires (SCJBA) rechazó los recursos de inaplicabilidad de ley y de nulidad. En paralelo, en el año 1997, Spoltore había presentado una denuncia ante la Inspección General de la SCJBA por la demora excesiva en el proceso, cuyo resultado fue un llamado de atención a la 
secretaria del tribunal interviniente. Sobre este punto, el Estado argentino reconoció parcialmente su responsabilidad por la violación de los derechos a las garantías judiciales y a la protección judicial.

El 9 de junio de 2020, la Corte IDH resolvió que el Estado argentino es responsable por la violación de los derechos reconocidos en los artículos 8.1 (garantías judiciales) y 25.1 (protección judicial) de la Convención Americana sobre Derechos Humanos, en relación con la obligación de respetar y garantizar dichos derechos, consagrada en el artículo 1.1 de la misma, por la violación del plazo razonable en el proceso judicial.

A su vez, consideró que el Estado es responsable por la violación del derecho a condiciones de trabajo equitativas y satisfactorias que aseguren la salud del trabajador, reconocido en el artículo 26 de la Convención Americana sobre Derechos Humanos, en relación con el acceso a la justicia, reconocido en los artículos 8.1 y 25.1

\section{II.5. Empleados de la fábrica de fuegos de Santo Antonio de Jesus vs. Brasil}

El 11 de diciembre de 1998 se produjo una explosión en una fábrica de fuegos artificiales ubicada en el municipio de Santo Antônio de Jesus, en el estado de Bahia, Brasil. Como consecuencia, fallecieron 60 personas, la enorme mayoría, mujeres trabajadoras pobres y afrodescendientes, algunas de ellas embarazadas. Además, en el lugar había niños y niñas cuyas madres no podían garantizarles el cuidado fuera de su lugar de trabajo. Todas las personas trabajaban de modo informal y percibían salarios muy bajos.

El lugar no contaba con las medidas de seguridad que deben existir en una fábrica dedicada a una actividad peligrosa, como es la manipulación de fuegos artificiales, ni las personas que allí trabajaban habían sido capacitadas para llevar adelante esa tarea. Y, aunque se encontraba autorizado para funcionar, el Estado no había llevado adelante ninguna tarea de control.

Con fecha 15 de julio de 2020, la Corte declaró la responsabilidad internacional de la República Federativa de Brasil por las violaciones a diversos derechos en perjuicio de 60 personas fallecidas y seis heridas en la explosión en una fábrica de fuegos artificiales en el municipio de Santo Antônio de Jesus, estado de Bahia, así como de 100 familiares de las personas fallecidas y sobrevivientes a la explosión. La Corte encontró que, como consecuencia de la explosión, fueron violados los derechos a la vida, integridad personal, trabajo en condiciones equitativas y satisfactorias, derechos de la niña y del niño, igualdad y no discriminación, protección judicial y garantías judiciales. En consecuencia, declaró que el Estado es 
responsable por la violación de los artículos 4.1, 5.1, 19, 24 y 26, en relación con el artículo 1.1 de la Convención Americana sobre Derechos Humanos.

\section{Estándares sobre el derecho al trabajo}

\section{III.1. Contenido y alcance del artículo 26 de la CADH en materia de derechos laborales}

Como se mencionó, la sentencia en el caso "Lagos del Campo" representó una ruptura, un giro en materia de derecho al trabajo. En ese sentido, implicó una oportunidad para que la Corte IDH se explaye en su análisis y su contenido como un derecho consagrado en el artículo 26 de la CADH y, por lo tanto, exigible de modo directo ante el Sistema Interamericano.

En efecto, en ese caso, la Corte IDH reiteró la interdependencia e indivisibilidad existente entre los derechos civiles y políticos, y los económicos, sociales y culturales, que deben ser entendidos de forma integral y conglobada como derechos humanos, sin jerarquía entre sí y exigibles en todos los casos ante las autoridades que resulten competentes para ello (11). En tal sentido, la Corte refirió específicamente al artículo 29.d de la $\mathrm{CADH}$, en tanto afirma expresamente que "ninguna disposición de la presente Convención puede ser interpretada en el sentido de: (...) d) excluir o limitar el efecto que puedan producir la Declaración Americana de Derechos y Deberes del Hombre y otros actos internacionales de la misma naturaleza" (12).

Luego, el tribunal regional observó que los derechos laborales reconocidos en el artículo 26 de la CADH son aquellos que se derivan de las normas económicas, sociales y sobre educación, ciencia y cultura contenidas en la Carta de la OEA, cuyos artículos $45 . \mathrm{b}$ y c, 46 y 34.g establecen que "el trabajo es un derecho y un deber social" y que debe prestarse con "salarios justos, oportunidades de empleo y condiciones de trabajo aceptables para todos". Asimismo, esas normas señalan que el derecho de los trabajadores y trabajadoras comprende el derecho a "asociarse libremente para la defensa y promoción de sus intereses" (13).

Al respecto, recordó que el artículo XIV de la Declaración Americana de Derechos y Deberes del Hombre prescribe que "toda persona tiene derecho al trabajo en condiciones dignas y a seguir libremente su vocación (...)". Tal disposición

(11) Corte IDH, caso "Lagos del Campo", párr. 141.

(12) Corte IDH, caso "Lagos del Campo", párr. 144.

(13) Corte IDH, caso "Lagos del Campo", párr. 143. 
resulta relevante, según el tribunal, para definir el alcance del artículo 26, dado que la Declaración Americana, constituye, en lo pertinente y en relación con la Carta de la Organización, una fuente de obligaciones internacionales.

\section{III.2. La estabilidad en el trabajo}

Los casos "Lagos del Campo", "Trabajadores Cesados de Petroperú" y "San Miguel Sosa", refieren específicamente a despidos de trabajadoras y trabajadores, por diversas razones y sometidos a diferentes regímenes de contratación.

Haciendo propio el contenido y alcance que le dio el Comité DESC al derecho al trabajo, la Corte IDH sostuvo que abarca el derecho a no ser privado de forma injusta del empleo, a la vez que determinó que: "el incumplimiento de la obligación de proteger se produce cuando los Estados Partes se abstienen de adoptar todas las medidas adecuadas para proteger a las personas sometidas a su jurisdicción contra las vulneraciones del derecho al trabajo imputables a terceros", lo cual incluye "el hecho de no proteger a los trabajadores frente al despido improcedente" (14).

En ese sentido, estableció el tribunal regional que la obligación estatal en materia de estabilidad en el trabajo:

se traduce en principio en los siguientes deberes: a) adoptar las medidas adecuadas para la debida regulación y fiscalización de dicho derecho; b) proteger al trabajador y trabajadora, a través de sus órganos competentes, contra el despido injustificado; c) en caso de despido injustificado, remediar la situación (ya sea, a través de la reinstalación o, en su caso, mediante la indemnización y otras prestaciones previstas en la legislación nacional). Por ende, el Estado debe disponer de mecanismos efectivos de reclamo frente a una situación de despido injustificado, a fin de garantizar el acceso a la justicia y la tutela judicial efectiva de tales derechos" (15).

Además, afirmó la Corte IDH que la estabilidad:

No consiste en una permanencia irrestricta en el puesto trabajo, sino que se debe respetar este derecho, entre otras medidas, otorgando debidas garantías de protección al trabajador, a fin de que, en caso de despido se realice bajo causas justificadas, lo cual implica que el empleador acredite las razones suficientes para imponer dicha sanción

(14) Corte IDH, caso “Lagos del Campo", párr. 147.

(15) Corte IDH, caso "Lagos del Campo", párr. 149. 
con las debidas garantías, y frente a ello el trabajador pueda recurrir tal decisión ante las autoridades internas, quienes verifiquen que las causales imputadas no sean arbitrarias o contrarias a derecho (16).

\section{III.3. La libertad de asociación en el ámbito del trabajo}

En lo que atañe a la violación de la libertad de asociación (artículo 16 de la $\mathrm{CADH}$, planteada en el caso "Lagos del Campo"), la Corte indicó que "la protección que reconoce el derecho a la libertad de asociación en el contexto laboral se extiende a organizaciones que, aun cuando tengan una naturaleza distinta a la de los sindicatos, persigan fines de representación de los intereses legítimos de los trabajadores" (17).

En ese sentido, afirmó el tribunal regional:

los representantes de los trabajadores de una empresa deben gozar de una protección eficaz contra todo acto que pueda perjudicarlos, incluido el despido por razón de su condición de representantes de los trabajadores, o de sus actividades derivadas de dicha representación. Por su parte, las autoridades nacionales deben garantizar que la imposición de sanciones que puedan resultar desproporcionadas no generen un efecto disuasivo en el derecho de los representantes de expresar y defender los intereses de los trabajadores (18).

Además, la Corte IDH reiteró que la libertad de asociación tiene dos dimensiones, dado que contempla el derecho del individuo de asociarse libremente y utilizar los medios apropiados para ejercer esa libertad, y en los integrantes de un grupo para alcanzar determinados fines en conjunto y beneficiarse de los mismos. Asimismo, para la Corte IDH, los derechos derivados de la representación de los intereses de un grupo tiene una naturaleza dual, pues recae tanto en el derecho del individuo que ejerce el mandato o designación como en el derecho de la colectividad de ser representada, por lo que la violación del derecho del primero (el representante) repercute en la vulneración del derecho del otro (el representado) (19).

(16) Corte IDH, caso “Lagos del Campo", párr. 150.

(17) Corte IDH, caso "Lagos del Campo", párr. 158.

(18) Corte IDH, caso "Lagos del Campo", párr. 160.

(19) Corte IDH, caso "Lagos del Campo", párr. 162. 


\section{III.4. Condiciones de trabajo equitativas y satisfactorias}

En el caso "Spoltore" la Corte IDH avanzó en definir el contenido de las condiciones equitativas y satisfactorias de trabajo, las que deben asegurar, entre otras cosas, la salud del trabajador. En ese sentido, concluyó que estas refieren al derecho a realizar las labores en condiciones que prevengan accidentes de trabajo y enfermedades profesionales.

Sobre este punto, la Corte consideró que las obligaciones que se derivan de este derecho "incluyen aspectos que tienen una exigibilidad inmediata, así como aspectos que tienen un carácter progresivo" (20). Respecto de las primeras, "los Estados deberán adoptar medidas eficaces a fin de garantizar el acceso sin discriminación a las salvaguardas reconocidas para el derecho a condiciones de trabajo que aseguren la salud del trabajador" (21). Entre estas obligaciones, la Corte considera que se encuentra "la obligación de poner a disposición del trabajador mecanismos adecuados y efectivos para que los trabajadores afectados por un accidente o enfermedad profesional puedan solicitar una indemnización" (22).

Respecto de las obligaciones de carácter progresivo, estas consisten en "la obligación concreta y constante de avanzar lo más expedita y eficazmente posible hacia la plena efectividad de dicho derecho, en la medida de sus recursos disponibles, por vía legislativa u otros medios apropiados" (23), lo que asimismo incluye la obligación de no regresividad.

En tanto, en el caso "Empleados de la fábrica de fuegos" la Corte concluyó que los Estados tienen la obligación de garantizar condiciones de trabajo equitativas y satisfactorias que garanticen la seguridad, salud e higiene y prevengan accidentes de trabajo, lo cual es especialmente relevante cuando se trata de actividades que implican riesgos significativos para la vida e integridad de las personas. En particular, los Estados deben regular, supervisar y fiscalizar las actividades peligrosas.

\section{III.5. Garantías judiciales y tutela judicial efectiva en materia laboral}

En los cincos casos bajo estudio la Corte IDH analiza el alcance de los derechos al debido proceso (artículo 8, CADH) y a la tutela judicial efectiva (artículo 25, $\mathrm{CADH}$ ) en el ámbito laboral. En particular, el Tribunal interamericano consideró que el derecho al trabajo incluye la obligación del Estado de garantizar los

(20) Corte IDH, caso “Spoltore”, párr. 97.

(21) Corte IDH, caso "Spoltore”, párr. 97.

(22) Corte IDH, caso "Spoltore”, párr. 97.

(23) Corte IDH, caso “Spoltore”, párr. 97. 
derechos de acceso a la justicia y a la tutela judicial efectiva en el ámbito público y en el ámbito privado de las relaciones laborales (24).

En el caso "Trabajadores Cesados de Petroperú", la Corte IDH declaró la responsabilidad internacional del Perú en tanto el Tribunal Constitucional que intervino no se encontraba debidamente conformado, lo que vulneró la independencia e imparcialidad de aquel órgano jurisdiccional nacional (25).

Por su parte, en "San Miguel Sosa", y en cuanto al modo en que debía valorarse la prueba, la Corte IDH afirmó:

Ante alegatos de persecución o discriminación política, represalia encubierta o restricciones arbitrarias indirectas al ejercicio de una serie de derechos, los jueces estaban en posición y obligación, por control de convencionalidad, de garantizar una protección judicial con las debidas garantías a las presuntas víctimas, analizando la motivación o finalidad real del acto impugnado más allá de las razones formales invocadas por la autoridad recurrida, así como los elementos contextuales e indiciarios relevantes señalados en el capítulo anterior (26).

Finalmente, en el caso "Spoltore", La Corte reiteró que el acceso a la justicia es uno de los componentes del derecho a condiciones de trabajo que aseguren la salud del trabajador. En particular, refirió que los Estados deben asegurar que los trabajadores afectados por un accidente o enfermedad profesional prevenible tengan acceso a mecanismos adecuados de reclamación, como los tribunales, para solicitar una reparación o indemnización. Puntualmente, el proceso iniciado por Spoltore se prolongó por más de 12 años y el Estado reconoció que dicha duración excesiva implicó una violación a la garantía del plazo razonable y el derecho a la protección judicial.

\section{III.6. Libertad de expresión y derechos políticos en el ámbito laboral}

En dos de los casos bajo análisis, los despidos estuvieron relacionados con el ejercicio de la libertad de expresión y con derechos políticos. Por ello, resultan de particular interés los estándares desarrollados por la Corte IDH sobre este tema.

Así, en el caso "Lagos del Campo", el tribunal regional sostuvo que "el ámbito de protección del derecho a la libertad de pensamiento y expresión resulta

(24) Corte IDH, caso “Trabajadores Cesados de Petroperú”, párr. 193.

(25) Corte IDH, caso "Trabajadores Cesados de Pretroperú", punto resolutivo 6.

(26) Corte IDH, caso “San Miguel Sosa”, párr. 192. 
particularmente aplicable en contextos laborales como el del presente caso, respecto del cual el Estado debe no solo respetar dicho derecho sino también garantizarlo, a fin de que los trabajadores o sus representantes puedan también ejercerlo" (27).

Por lo demás, en aplicación de los estándares específicos en materia de libertad de expresión, la Corte IDH enfatizó que "el despido puede constituir la máxima sanción de la relación laboral, por lo que es fundamental que la misma revista de una necesidad imperiosa frente a la libertad de expresión y que tal sanción esté debidamente justificada ('despido justificado')" (28).

En cuanto a la protección especial de la libertad de expresión de los representantes de los trabajadores, afirmó la Corte IDH:

Las manifestaciones del señor Lagos del Campo, como representante de los trabajadores, además de rebasar el ámbito privado, tenían una relevancia o impacto tal como para trascender no sólo el interés colectivo de los trabajadores de la empresa sino del gremio (de comuneros) relacionado con las Comunidades Industriales en general. Por tanto, de los hechos del presente caso se desprende que la información contenida en las declaraciones del señor Lagos del Campo eran de interés público y por ende contaban con un nivel reforzado de protección (29).

Por su parte, en el caso "San Miguel Sosa" y con énfasis en los efectos que la discriminación política puede acarrear en los ámbitos laborales, el tribunal interamericano concluyó:

La terminación arbitraria de la relación laboral de las presuntas víctimas con el Consejo Nacional de Fronteras constituyó una forma de desviación de poder, pues se utilizó una cláusula establecida en su contrato como velo de legalidad para encubrir la verdadera finalidad de tal medida, a saber: una represalia en su contra por haber ejercido legítimamente sus derechos de participación política y libertad de expresión. Es decir, ellas fueron objeto de discriminación política mediante un despido arbitrario, el cual ocurrió en un contexto de denuncias de despidos semejantes y de otras formas de represalia para quienes habían decidido ejercer sus libertades al firmar por la solicitud de referendo. Así, su despido tenía la intención encubierta de acallar y desincentivar la disidencia política, pues fue instrumentalizado para

(27) Corte IDH, caso “Lagos del Campo”, párr. 96.

(28) Corte IDH, caso "Lagos del Campo", párr. 125.

(29) Corte IDH, caso "Lagos del Campo", párr. 116 
que otras personas se vieran amedrentadas de participar políticamente y de expresar sus ideas y opiniones (30).

\section{III.7. La igualdad y la no discriminación y el derecho al trabajo}

En el caso "Empleados de la fábrica de fuegos" la Corte IDH realiza un rico desarrollo en materia de igualdad y no discriminación y el derecho al trabajo, en el que traza un vínculo entre las condiciones estructurales e interseccionales de discriminación que sufre la población de Santo António de Jesús y el modo en el que se enraízan trabajos precarios, informales y, como en el caso, en extremo peligrosos.

Si bien en análisis específico que lleva adelante el tribunal regional en materia de igualdad excede el objeto de este trabajo, vale hacer una reseña de algunos puntos explorados en la sentencia, que constituyen en sí mismos un avance significativo de la jurisprudencia interamericana sobre la cuestión.

Como se mencionó, en la fábrica en la que se produjo el fatal accidente la enorme mayoría de las trabajadoras eran mujeres pobres, afrodescendientes, algunas de ellas embarazadas, que concurrían al lugar junto a sus hijos e hijas. Esta intersección de factores de discriminación las ubicó en un lugar de particular vulnerabilidad(31). Primeramente, la Corte analiza la discriminación por razón de la pobreza y determina que, si bien no es una categoría contenida en el artículo 1.1, puede interpretarse como parte de la "posición económica", que sí está contenida en esa disposición(32).

$\mathrm{Al}$ respecto, la Corte IDH reafirmó que los Estados están obligados a adoptar medidas de acción positivas para revertir las situaciones de discriminación que sufren determinados grupos, a la vez que recae sobre ellos el deber de especial protección con respecto a prácticas de terceros. Esta visión de la igualdad —que algunos autores denominan "igualdad como no sometimiento" (33) — impacta, asimismo, en las consideraciones en torno a la reparación, como se verá más adelante.

(30) Corte IDH, caso “San Miguel Sosa”, párr. 221.

(31) Al respecto, la autora Kimberle Crenshaw refirió a la interseccionalidad para "señalar las distintas formas en las que la raza y el género interactúan, y cómo generan las múltiples dimensiones de las mujeres negras en el ámbito laboral" (Crenshaw, 1991, p. 1244).

(32) Corte IDH, caso “Empleados de la fábrica de fuegos", párr. 185.

(33) Sobre este punto, Roberto Saba (2016) sostiene que "Esta visión de la igualdad también operaría como guía para el diseño de políticas públicas que, por un lado, no deberían contribuir a perpetuar la situación de subordinación de grupos y, por el otro, deberían tender a desmantelar las estructuras sociales que producen esa subordinación" (p. 81). 
Respecto de este caso, la Comisión sostuvo que la situación de pobreza y el incumplimiento por parte del Estado de sus obligaciones se vincula con la violación del derecho a condiciones equitativas y satisfactorias de trabajo sin discriminación. De este modo, la Corte entendió:

Así, el hecho de que una actividad económica especialmente riesgosa se haya instalado en la zona está relacionado con la pobreza y marginación de la población que allí residía y reside. Para los habitantes de los barrios de origen de las trabajadoras de la fábrica de fuegos, el trabajo que allí les ofrecían era la principal, sino la única opción laboral, pues se trataba de personas con muy bajo nivel de escolaridad y alfabetización, que además eran perfiladas como poco confiables y, por estas razones, no podían acceder a otro empleo. Al respecto, los Principios Rectores sobre Extrema Pobreza y Derechos Humanos reconocen que 'las personas que viven en la pobreza se ven enfrentadas al desempleo o el subempleo y al trabajo ocasional sin garantías, con bajos salarios y condiciones de trabajo inseguras y degradantes' (34).

\section{Medidas de reparación}

Con respecto a las reparaciones, además de las indemnizaciones pecuniarias ordenadas para reparar el daño material e inmaterial padecido, en los casos "Lagos del Campo", "San Miguel Sosa" y "Trabajadores cesados de Petroperú" (por estar en juego el derecho a la estabilidad laboral) se discutió si procedía la reincorporación de los/as trabajadores/as.

En estos dos últimos -en los que se trataba de trabajadores del sector público-, la Corte IDH dio razones por las cuales entendió que no procedía la reinstalación en sus puestos de trabajo. En "Trabajadores cesados de Petroperú", afirmó que "transcurridos aproximadamente 25 años de los ceses laborales ocurridos en el presente caso, la reincorporación o reposición de los trabajadores en sus antiguos cargos o en otros análogos enfrenta diversos niveles de complejidad y operatividad, en particular, por las modificaciones estructurales que han ocurrido en Petroperú, Enapu, MEF y Minedu" (35).

Del mismo modo, en "San Miguel Sosa", manifestó que "en razón de las circunstancias específicas de este caso, no corresponde ordenar la reinstalación o reincorporación de las víctimas a cargos en la administración pública, por lo cual

(34) Corte IDH, caso "Empleados de la Fábrica de fuegos", párr. 189.

(35) Corte IDH, caso “Trabajadores cesados de Petroperú", párr. 231. 
los daños producidos por el despido arbitrario han sido ya tomados en cuenta al fijar la indemnización compensatoria" (36).

En el caso "Empleados de la fábrica de fuegos", la Corte IDH avanzó en un esquema de reparaciones novedoso y con vocación transformadora (37). En efecto, el tribunal regional resolvió, en cuanto a la garantía de no repetición:

Con el fin de frenar el funcionamiento de las fábricas clandestinas y/o que operan en desacuerdo con las normas sobre el control de actividades peligrosas, y de garantizar condiciones de trabajo equitativas y satisfactorias en esos ambientes, el Estado debe adoptar medidas para implementar una política sistemática de inspecciones periódicas en los locales de producción de fuegos artificiales, tanto para que se verifiquen las condiciones de seguridad y salubridad del trabajo, como para que se fiscalice el cumplimiento de las normas relativas al almacenamiento de los insumos (38).

Respecto de la situación de especial vulnerabilidad en la que se encontraban las trabajadoras de la localidad de Santo Antonio de Jesús, la Corte ordenó al Estado:

En el plazo máximo de dos años (...) diseñe y ejecute un programa de desarrollo socioeconómico especialmente destinado para la población de Santo Antônio de Jesus, en coordinación con las víctimas y sus representantes (...) Dicho programa debe hacer frente, necesariamente, a la falta de alternativas de trabajo, especialmente para las y los jóvenes mayores de 16 años y mujeres afrodescendientes que viven en condición de pobreza. El programa debe incluir, entre otros: la creación de cursos de capacitación profesional y/o técnicos que permitan la inserción de trabajadoras y trabajadores en otros mercados laborales, como el comercio, el agropecuario, la informática, entre otras actividades económicas relevantes en la región; medidas orientadas a enfrentar la deserción escolar causada por el ingreso de menores de edad al mercado laboral, y campañas de sensibilización en materia de derechos laborales y riesgos inherentes a la fabricación de fuegos artificiales (39).

(36) Corte IDH, caso “San Miguel Sosa”, párr. 242.

(37) Al respecto, en el caso "González y otras vs México" (conocido como "Campo Algodonero"), la Corte IDH sostuvo que en casos de desigualdad estructural "las reparaciones deben tener una vocación transformadora de dicha situación, de tal forma que (...) tengan un efecto no sólo restitutivo sino también correctivo" (párr. 450).

(38) Corte IDH, caso "Empleados de la fábrica de fuegos", párr. 287.

(39) Corte IDH, caso "Empleados de la fábrica de fuegos", párr. 289. 


\section{Conclusiones}

En este artículo se intentó llevar adelante una breve sistematización de los estándares que emanan de las sentencias de la Corte IDH en cinco casos que involucran violaciones al derecho al trabajo, en lo que se constituyó como un cambio en la jurisprudencia interamericana respecto e los DESCA. Tal y como se observa, esto implicó un avance sustancial para la protección de un derecho fundamental para el disfrute de otros derechos humanos.

El contexto que atraviesa desde hace ya mucho tiempo la región sedimenta exclusiones, vulneraciones de derechos e índices altísimos de pobreza y precarización, que impacta de modo diferenciado a determinados grupos, algo que se evidenció en el caso "Empleados de la fábrica de fuegos".

Sin embargo, este giro llega con desafíos. Si bien los obligados al cumplimiento de las obligaciones contenidas en los instrumentos internacionales son los Estados, resulta clave avanzar en materia de responsabilidad empresaria. En efecto, las afectaciones al derecho al trabajo también pueden - y en ocasiones sucedeimpactar negativamente en los Estados. Por ejemplo, en materia de recaudación tributaria y de protección social en aquellos países con altos índices de informalidad laboral. Esto, a su vez, refuerza las obligaciones de los Estados en materia de inspecciones, algo que también se discutió en algunos de los casos repasados.

Si bien el mundo del trabajo está, hace ya mucho tiempo, en plena transformación - y eso plantea importantes conflictos en torno al trabajo y las protecciones que de él se derivan- es bienvenida la jurisprudencia interamericana en la medida en que pavimenta un camino de reconocimiento y reparación. Sobre este punto, la sentencia en el caso "Empleados de la fábrica de fuegos" resulta fundamental para pensar las políticas que se pueden implementar en materia de discriminación estructural y trabajo, en particular en un continente signado por, como se mencionó, la precarización laboral, los trabajos atípicos y la informalidad.

También como desafío, resta pensar las reparaciones en materia de derecho colectivo y de libertad de expresión. Teniendo en cuenta que la afectación de esos derechos puede tener un efecto disuasorio para el resto de las trabajadoras y trabajadores, una reparación económica puede resultar insuficiente.

En definitiva, la Corte IDH inició el que deseamos sea un próspero camino para la protección de los derechos económicos, sociales, culturales y ambientales en general y del derecho al trabajo en particular. Resta, como suele ocurrir, la aplicación del control de convencionalidad por parte de los tribunales domésticos para robustecer la garantía de derechos — cada vez más - fundamentales. 


\section{Bibliografía}

Abramovich, V. y Courtis, C. (2009). Apuntes sobre la exigibilidad judicial de los derechos sociales. En R. Gargarella (ed.), Teoría y crítica del derecho constitucional, T. II, Derechos. Buenos Aires: Abeledo Perrot.

Calderón Gamboa, J. (2018). La puerta de la justiciabilidad de los derechos económicos, sociales, culturales y ambientales en el Sistema Interamericano: relevancia de la sentencia Lagos del Campo. En E. Ferrer Mac-Gregor; M. Morales Antoniazzi y R. Flores Pantoja (coord.), Inclusión, Ius commune y justiciabilidad de los DESCA en la jurisprudencia interacamericana: el caso Lagos del Campo y los nuevos desafíos (pp. 333-374). Ciudad de México: Instituto de Estudios Constitucionales del Estado de Querétaro.

Cancado Trindade, A. (1997). La justiciabilidad de los derechos económicos, sociales y culturales en el plano internacional. Revista Lecciones y Ensayos, № 69, 70 y 71 . Recuperado de http://www.derecho.uba.ar/publicaciones/lye/pub_lye numeros_69_70_71.php

Crenshaw, K. (1991) Mapping the margins: Intersectionality, identity politics and violence against women of color. Stanford Law Review. Vol. 43. No 6 (pp. 1241-1299). Recuperado de https://www.jstor.org/stable/1229039?seq=1

Pinto, M. (2004). Los derechos económicos, sociales y culturales y su protección en el sistema universal y en el sistema interamericano. 40 Revista del IIDH (pp. 25-86). Recuperado de https://www.corteidh.or.cr/tablas/R08064-2.pdf

Saba, R. (2016). Más allá de la igualdad formal antes la ley. ¿Qué les debe el Estado a los grupos desaventajados? Buenos Aires: Siglo Veintiuno Editores.

Fecha de recepción: 28-03-2021

Fecha de aceptación: 27-06-2021 
